\title{
Air velocity and pollutant profiles in Krakow
}

\author{
E. Tomczak, W. Kamiński, K. Kamiński \& J. Petera \\ Faculty of Process and Environmental Engineering, \\ Technical University of Lodz, Poland
}

\begin{abstract}
This paper presents a numerical grid model based on the finite element method, which enables a computer simulation of air mass flow and pollutant propagation over Krakow. To construct a calculation domain the information from a digital map was used, which allowed us to include an active surface layout into the model.

Methods for implementation of velocity fields from a mesoscale meteorological pre-processor as a boundary condition for the model in the city scale were developed. Air velocity profiles over Krakow, calculated from the MM5 meteorological model data are presented. Additionally, the evolution of a concentration field for a hypothetical tracer release in the city was simulated.

Keywords: air flow field, modelling of pollutants propagation, meso- and macroscale model.
\end{abstract}

\section{Introduction}

A key problem in the modelling of pollutant dispersion over strongly urbanised areas is to reflect the effect of local factors on the formation of a velocity profile. A wind field over the city is characterised by a significant spatial differentiation, which in turn determines the processes of transport and dispersion in lower layers of the atmosphere. As a result of the impact of obstacles in the city, flow turbulence increases, the so-called tunnel winds resulting from deep street canyons, flow swirls, and even streams in the direction opposite to average wind are formed [1,2]. It is also important to take into account velocity profiles varying in time, particularly when meteorological conditions over the considered area are changing. Data from the mesoscale 
meteorological model MM5 (Penn State University/National Centre for Atmospheric Research's Mesoscale Model), was used in the calculations for Krakow.

The idea of the proposed research is to develop a computer model of air pollutant dispersion in lower layers of the atmosphere over Krakow using the finite element method FEM and a general Euler-Lagrange approach [3,4]. The model will reflect topographic features and buildings on a given area, as well as arterial roads. These elements have a fundamental effect on the dispersion of air pollutants on an urbanised area. The similar approach was presented in our previous paper which took Lodz (city in Poland) as an example [5].

The proposed method is a compromise between too general mesoscale models and microscale models, whose application in the described task would require a significant processor capacity.

\section{Construction of a calculation domain}

The proposed method allows us to include in the calculation domain geometry the elements typical of strongly urbanised areas, i.e. building structure and arterial roads, as well as the natural surface features. For this purpose a digital map was used. The map contained coordinates which describe topography of Krakow and also information on the character of built-up areas and location of main roads. Basing on the digital map sub-regions with relatively uniform buildings in view of their height were selected. Additionally, on the urban builtup areas the network of arterial roads constituting ventilation ducts for the city was distinguished. The roads were classified according to their type and width, proportionally to the ventilating functions. A 3D calculation domain grid, containing the above elements, was constructed. In numerical calculations our own software was used, which allowed us to consider many details that made the model closer to reality and which were not available in a typical commercial software.

At the first stage of the calculation process, the Navier-Stokes and mass conservation equations were integrated, which enabled determination of velocity profiles of the flowing air masses [6]. At the second stage, the equation of pollutant transport in the atmosphere was solved basing on the previously formed velocity profile. As a result, a continuous concentration profile and its evolution in time were obtained.

To define boundary conditions, the authors used meteorological data concerning the direction and velocity profile of air flowing over the studied area, taken from MM5 the mesoscale prediction model.

To determine precisely the construction of a calculation domain, a digital map describing topographic features of Krakow and its neighbourhood, i.e. the area $36.1 \times 23.6 \mathrm{~km}$ (Figure 1) was used.

Additionally, basing on an electronic map of the road system in the city, a representation of arterial roads which can be ventilating ducts for Krakow was included in the model grid (Figure 2). The 3D calculation domain contains a space from the ground or building surface (depending on the character of surface cover) to the height $700 \mathrm{~m}$ above sea level. 


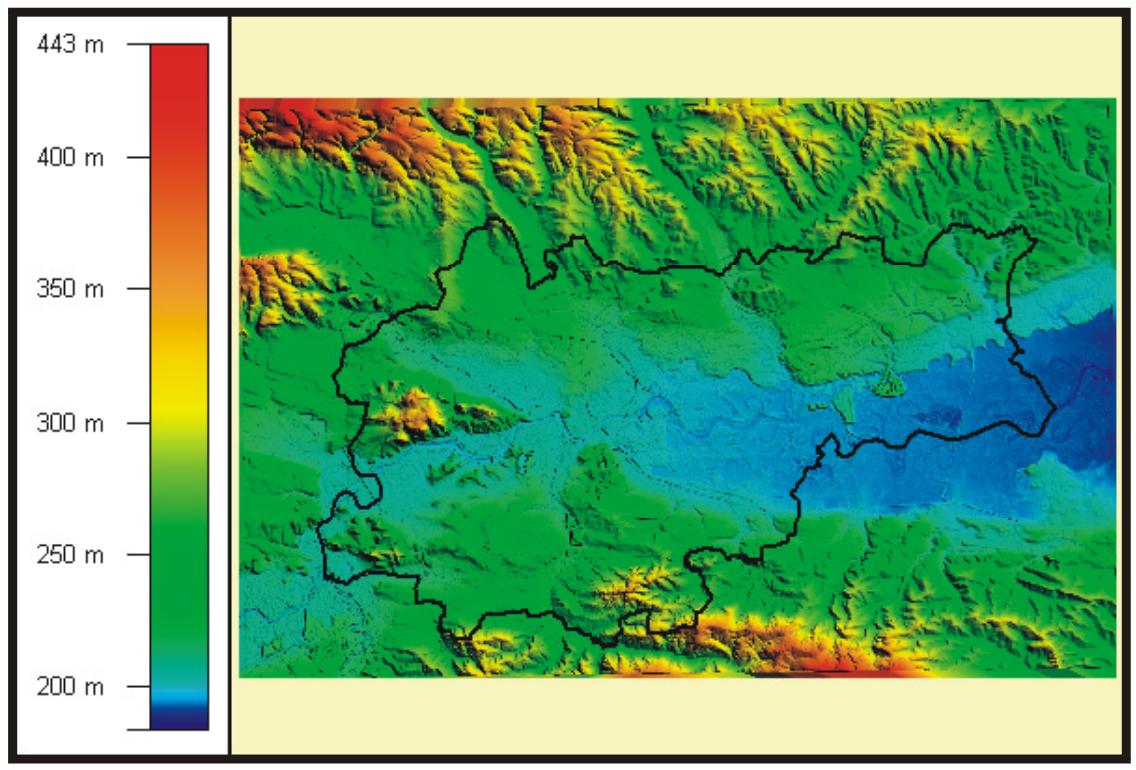

Figure 1: Topographic features of Krakow and neighbourhood.

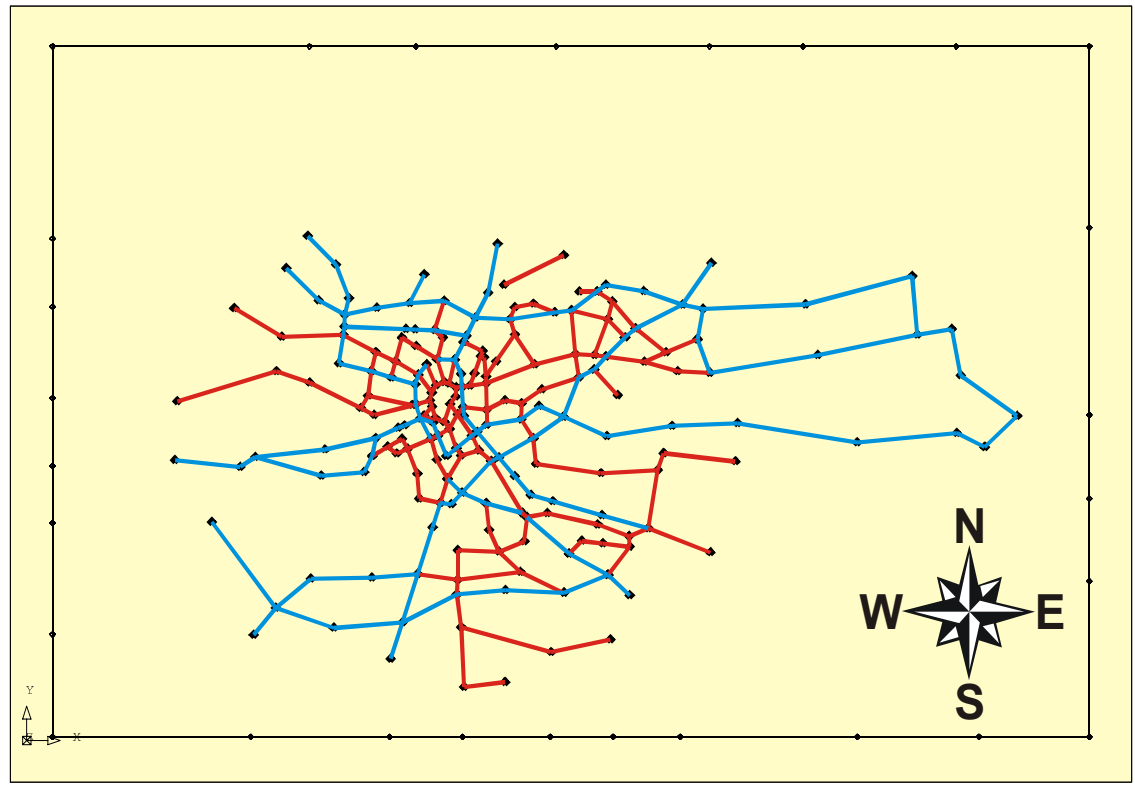

Figure 2: $\quad$ Arterial roads in Krakow included in the model. 


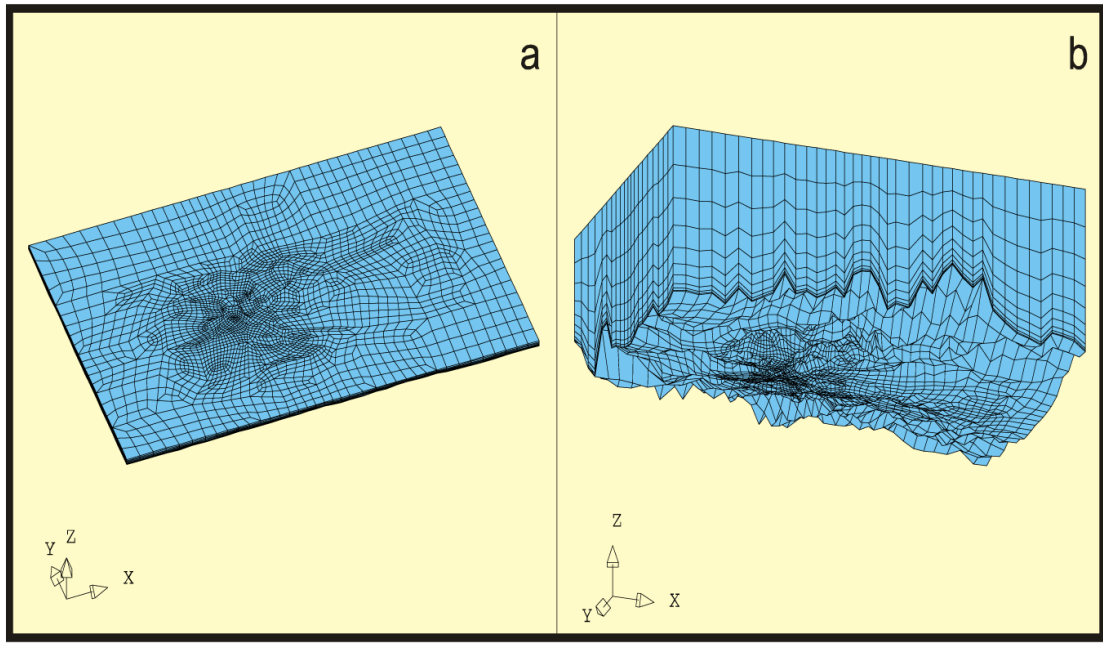

Figure 3: A 3D grid of the calculation domain a) real dimensions, b) vertical dimension extended for better visualisation.

Basing on the digital map, each point of the calculation grid was referred to a real position above sea level. The grid with a variable calculation mesh was so constructed as the higher resolution encompassed the town area with dense down-town buildings and was decreasing while receding from the city centre. The grid of the model was concentrated in the near-surface zone, where the highest differentiation of the velocity profile was expected.

An irregular shape of the elements of the calculation grid was a result of the representation of arterial roads and the Vistula river in the model (Figure 3). These obstacles were located on the basis of the electronic map which contained detailed information on the structure of the road system in Krakow.

\section{A mathematical description of air velocity profile modelling}

At the first stage of the calculation process velocity profiles of air flowing over the city were determined. The continuity equation with liquid incompressibility assumption and Navier-Stokes equation for three directions were used to describe air flow over Krakow.

$$
\begin{gathered}
\nabla \cdot \mathrm{u}=0 \\
\nabla \cdot\left(\left(\mu+\mu_{\mathrm{t}}\right)\left(\nabla \mathrm{u}+(\nabla \mathrm{u})^{\mathrm{T}}\right)\right)-\nabla \mathrm{p}-\rho \mathrm{g}=0
\end{gathered}
$$

The so-called one-equation turbulence model ( $K$-model) was included to liquid motion (eqn. (3)). This allowed us to take into account the turbulent character of air flow. Turbulent viscosity $\mu_{t}$ expressed by the kinetic energy of fluctuation $K$ was introduced eqn. (4). The $K$-model requires relatively small 
calculation outlays, and the obtained results are comparable with more complicated models of turbulence, as e.g. k- $\varepsilon$ [2].

$$
\begin{gathered}
\nabla \cdot\left(\left(\mu+\frac{\mu_{\mathrm{t}}}{\sigma_{\mathrm{K}}}\right) \nabla \mathrm{K}\right)+\mu_{\mathrm{t}} \gamma^{2}-\rho \mathrm{C}_{\mathrm{D}} \frac{\mathrm{K}^{3 / .2}}{1_{\mu}}=0 \\
\mu_{\mathrm{t}}=\rho \mathrm{C}_{\mu} \mathrm{K}^{1 / 2} 1_{\mu}
\end{gathered}
$$

where

$$
1_{\mu}=\kappa \delta
$$

$\delta$ - distance from the nearest wall, $\gamma$ - local shearing rate, $\kappa$ - von Karman constant, $\sigma_{\mathrm{K}}-$ turbulent Prandtl number, $\mathrm{C}_{\mathrm{D}}, \mathrm{C}_{\mu}-$ empirical coefficients.

On the surface limiting the calculation domain from the bottom, the following boundary conditions were applied:

$\mathrm{u}=0$ - zero components of velocity vectors $\mathrm{u}$ in all three directions,

$\mathrm{K}=0$-kinetic energy of fluctuation $K$ equal to zero.

On the remaining surfaces, where $\mathrm{u}$ and/or $\mathrm{K}$ were not defined, zero components of momentum flux and/or turbulent energy in normal direction were imposed:

$$
\begin{gathered}
\left(-\mathrm{p} \cdot \mathrm{I}+\left(\mu+\mu_{\mathrm{t}}\right)\left(\nabla \mathrm{u}+(\nabla \mathrm{u})^{\mathrm{T}}\right)\right) \cdot \mathrm{n}=0 \\
\frac{\mathrm{dK}}{\mathrm{dn}}=0
\end{gathered}
$$

For a simplified representation of the most important transport roads, on the lines which corresponded to arterial roads, the condition of zero velocity components in horizontal directions was assumed. The calculated values were corrected by drag coefficients which were selected taking into account the widths of arterial roads, and also their importance for city ventilation. In the case of Krakow two categories of ventilating ducts were distinguished (Figure 2).

\subsection{Examples of simulation results}

A method was developed to include time-variable wind field in the presented model by implementing boundary conditions in the form of velocity profiles from the meteorological model of a lower resolution.

Average, hourly velocity profiles of $28 \mathrm{Feb}$. 2006, generated by MM5 meteorological pre-processor, interpolated to the height $700 \mathrm{~m}$ above sea level were used in the presented results of the simulation. Since the data from the MM5 model referred to the grid with mesh size $6 \mathrm{~km} \times 6 \mathrm{~km}$, it was necessary to 


\section{Air Pollution XV}

apply the interpolation to model resolution in the city scale, i.e. transfer to the macroscale model. The finite element method was used in the developed interpolation procedure.

As a result of numerical calculations (the first stage) the air velocity profiles over Krakow in the entire 3D calculation domain shown in Figure 4 were obtained.

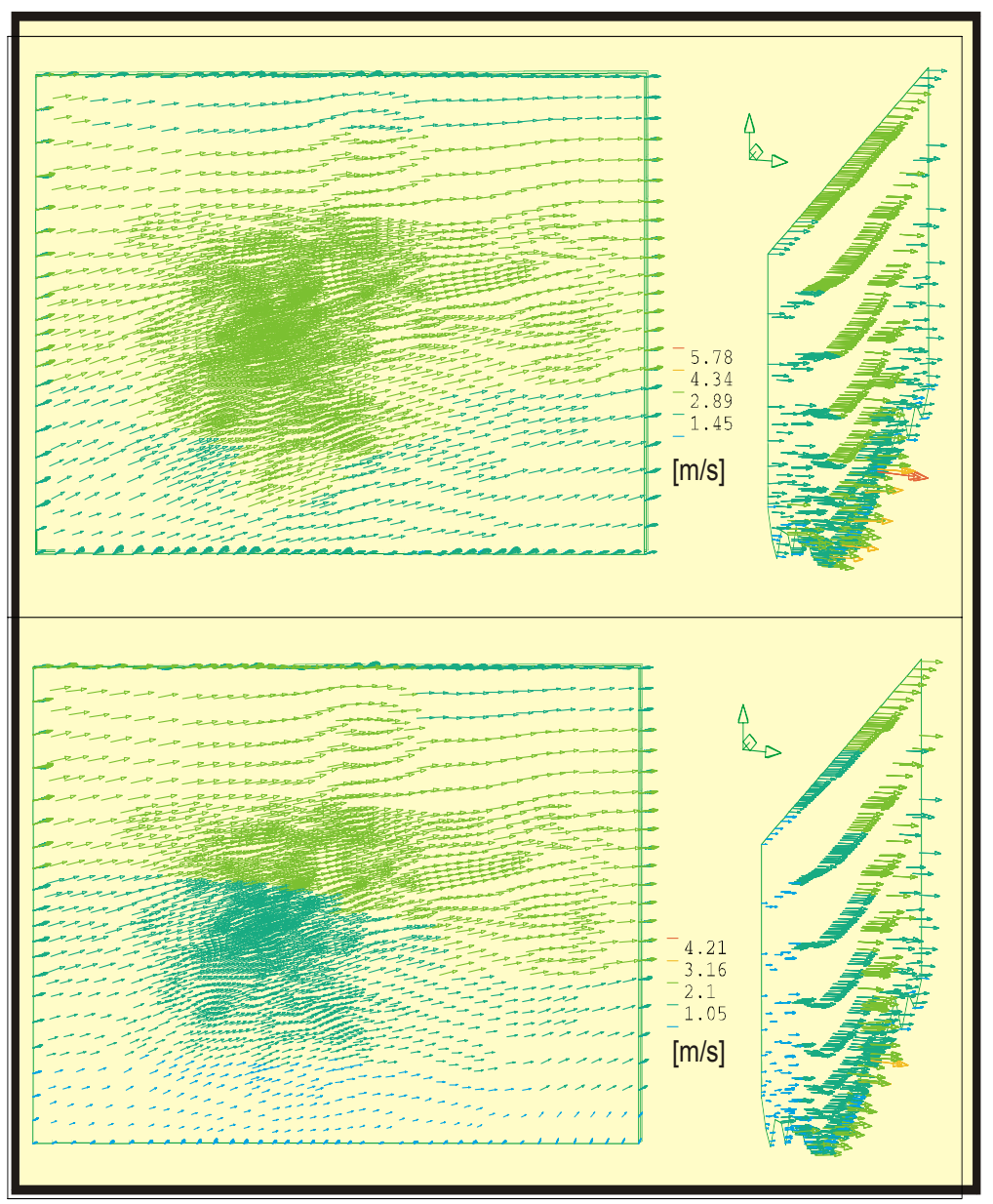

Figure 4: Velocity profiles for boundary conditions obtained from MM5 on $28 \mathrm{Feb} .2006$ a) 12:00 GMT + 1H b) 12:00 GMT + 5H.

\section{A mathematical description of pollutant dispersion models}

At the second stage, using the previously determined velocity profiles, the advection-diffusion pollutant transport equation was solved. In numerical calculations the original Lagrange algorithm was used (eqn. (9)). 


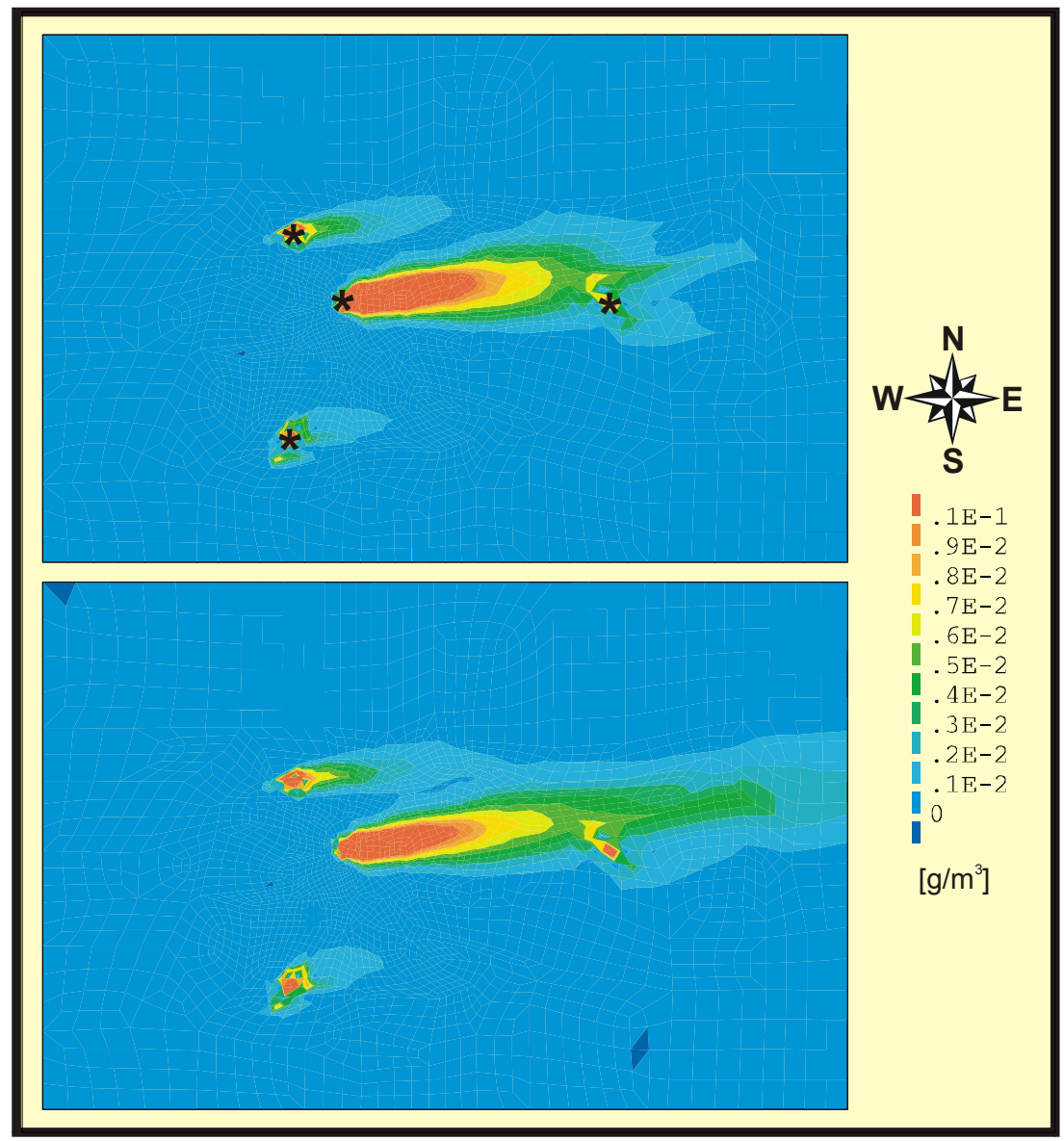

Figure 5: Concentration profiles of pollutants emitted on building level in pointsdenoted by symbol *, a) after $1 \mathrm{~h}$ since the incident b) after $5 \mathrm{~h}$ since the incident.

$$
\begin{aligned}
\frac{D c}{D t} & =\nabla \cdot\left(\left(D+D_{t}\right) \nabla c\right)+Q \\
c & =f(x(t), y(t), z(t), t)
\end{aligned}
$$

\subsection{Examples of simulation results}

The wind velocity profiles allowed us to simulate the dispersion of a hazardous substance (tracer), released for instance as a result of industrial accident in the city $(0.2 \mathrm{~kg} / \mathrm{s}$ at each point $)$. In modelling of this phenomenon variable meteorological conditions referring to wind velocity and direction were taken into account. The examples of calculations are illustrated in Figure 5. 


\section{Concluding remarks}

A three-dimensional numerical macromodel is proposed. The model is a compromise between mesoscale models, in which it is impossible to include the effect of local factors on velocity profile formation and pollutant transport processes. Macroscale models for the whole city do not require a significant processor capacity.

A method referring to time-variability of the velocity profile in the model in the city scale, using the so-called nesting in the meteorological model of lower resolution (MM5), was proposed.

The procedure enables a simulation of hypothetical emissions of hazardous substances which take place in different points in the city, for different meteorological conditions referring to the velocity and direction of flow of air over the tested area.

This will allow us to formulate probable scenarios of the evolution of hazard propagation. Parts of Krakow particularly exposed to elevated levels of deposition will be indicated, which can be useful in planning rescue operations to minimise effects of incidents.

Reliability of predictions of the proposed macromodel depends to a large extent on the quality of data generated by the meteorological preprocessor.

\section{Nomenclature}

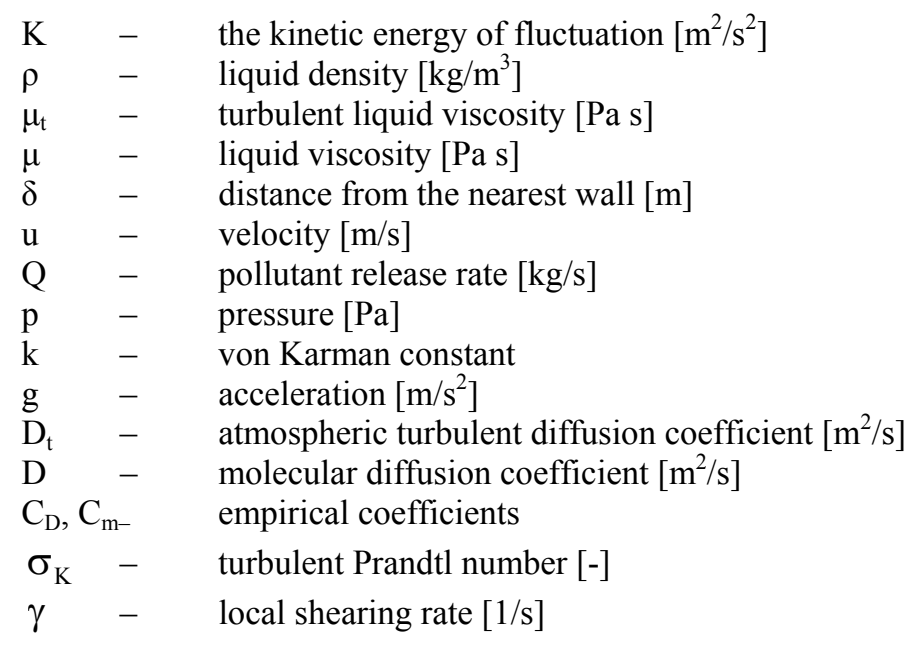

\section{Acknowledgements}

The research project no. 3 T09C 03129 was financed from the Polish funds for science in the years $2005 / 2006$. 


\section{References}

[1] Klaic Z.B., Nitis T., Kos I., Moussiopoulos N., Modification of the local winds due to hypothetical urbanization of the Zagreb surroundings, Meteorol. Atmos. Phys., 1-2,79, pp. 1-12, 2002.

[2] Axell L.B. and Liungman O., A one-equation turbulence model for geophysical applications: comparison with data and $\mathrm{k}-\varepsilon$ model, Environmental Fluid Mechanics, 1, pp. 71-106, 2001.

[3] Zienkieiwicz O.C., Taylor R.L., The finite element method, 3, 5th ed. Butherworth-Heineman, Oxford, 2000.

[4] Petera J. Nassehi V., A new two-dimensional finite element model for the shallow water equations using a Lagrangian framework constructed along fluid particle trajectories, Int. J. Numer. Methods Engng. 39, pp. 41594182, 1996.

[5] Kaminski K., Kaminski W., Petera J., A three-dimensional numerical model of air pollutant dispersion, Air Pollution XIII, (ed.) C.A. Brebbia, WIT Press, pp. 39-48, 2005.

[6] Nassehi V., Petera J., A new least-squares finite element model for combined Navier-Stokes and Darcy flows in geometrically complicated domains, Int. J. Numer. Methods Engng., 37, pp. 1609-1620, 1994. 